\title{
AS CULTURAS DE AFRO-DESCENDENTES EM CURRÍCULOS
} NA FORMAÇÃO DE PROFESSORAS*

\section{Nilda Alves}

\section{RESUMO}

O texto é trabalhado a partir de pesquisa desenvolvida, de 2005 a 2008, em torno da questão da riqueza das culturas africanas e de suas expressões no Brasil e as possibilidades que o trabalho em torno de artefatos culturais pode trazer às necessidades curriculares de auto-conhecimento e conhecimento do outro como legítimo Outro, na superação de preconceitos, pelo trabalho conjunto sobre questões históricas e imagens.

\section{PALAVRAS-CHAVES}

Currículos escolares; Culturas; Artefatos culturais; Formação de professoras ; Imagens

\section{THE AFRICAN-DESCENDANTS CULTURES IN CURRICULUM IN TEACHERS EDUCATION}

\begin{abstract}
The text is developed from research conducted, from 2005 and 2008, around the question of the richness of African cultures and their expression in Brazil, as well as the possibilities that working around cultural artifacts can bring to the curricular needs of self-knowledge and knowledge of the other as the legitimate Other, in the overcoming of prejudices, through work on historical questions and images.
\end{abstract}

\section{KEY WORDS}

School curricula; Cultures; Cultural artifacts; Teacher education; Images.

\footnotetext{
* Participam, atualmente, do Grupo de pesquisa: 1) como pós-doutorandos: Stela Guedes Caputo (bolsista Prodoc/CAPES), Carlos Eduardo Ferraço (bolsista CNPq; prof.da UFES) e Aristóteles Berino (prof da UFRRJ); 2) como doutorandos: Dirceu Castilho Pacheco; Marcio Romeu (bolsista CNPq); Martha Cupollillo; Nívea Andrade (bolsita TC5/FAPERJ); 3) como mestrandos: Alessandra Nunes Caldas (bolsista TC4/Faperj); Rosangela Lannes (bolsista CAPES); 4) como bolsista TC5/Faperj: Claudia Chagas; 5) como bolsista Proatec/UERJ: Isabel Machado; 6) como bolsista IC/CNPq: Perseu Silva; como voluntárias: Ana Paula Benjamin dos Santos (ex-bolsista IC/CNPq); Maria Cecília Castro (ex-bolsista IC/Faperj). O feminino do título tem a ver com decisão político-acadêmica de longa data.
} 
Parte considerável do mundo intelectual ainda se encontra petrificada na tradição milenar do iconoclasmo, parte também considerável do mundo artístico, científico e militante vem descobrindo que a cultura, a ciência e a civilização dos séculos XIX e XX são impensáveis sem o papel estrutural e constitutivo nelas desempenhado pelas imagens (da iconografia científica, da fotografia, do cinema, da televisão e dos novos meios digitais). Essa segunda parte da humanidade aprendeu não apenas a conviver com as imagens, mas também a 'pensar com as imagens' e a construir com elas uma civilização complexa e instigante. Na verdade, hoje estamos realmente em condições de avaliar a extensão e a profundidade de todo o acervo iconográfico construído e acumulado pela humanidade, apesar de todos os interditos, pois somente agora nos é possível compreender a natureza mais profunda do discurso iconográfico, isso que poderíamos chamar de 'linguagem das imagens', capaz de expressar realidades diferentes, historicamente abafadas pelo tacão do iconoclasmo (MACHADO, 2001, p. 32)

Há muito, venho trabalhando nas pesquisas de currículos que coordeno, com a presença de artefatos culturais nos espaçostempos ${ }^{1}$ educativos, compreendendo a necessidade de articular o 'uso' da produção material com os significados e valores que atuam na redes cotidianas de viver. Nesses processos, fomos percebendo que são complexos os modos como certos conhecimentos e certas significações são ‘encarnados’ em nós. Nesse sentido, tenho trabalhado, mais recentemente, com os preconceitos, entendidos como "valor com sinal negativo”. Lentamente e com grande esforço, vamos compreendendo os processos pelos quais esses conhecimentos e significações vão sendo ‘encarnados’ em nós, relacionando-os com o que BOULIER (1992) chama de 'tecnologias mudas', aquelas que não nos contam suas origens, o que hoje se coloca como um problema urgente a resolver, em currículos.

Buscando compreender os diferentes processos de contato e uso com uma nova tecnologia e com velhos valores que nos marcam, esse autor desenvolve idéias sobre a possibilidade que temos de compreender esses complexos processos, lembrando que

\begin{abstract}
o modo de usar transforma-se em um catalisador notável das tensões encontradas na vida quotidiana em face das proposições dos técnicos. Os fracos esforços de tradução feitos por esses últimos são, por vezes, superados pela invenção prodigiosa dos usuários: eles conduzem, algumas vezes, a insucessos comerciais e a sub-utilizações notórias. Trabalhar para elucidar as condições de uma didática das técnicas é, agora, tanto uma questão industrial e comercial, como uma questão cultural para evitar o agravamento da tendência na direção de uma sociedade dual que parece estar às nossas portas (p. 245).
\end{abstract}

\footnotetext{
${ }^{1}$ A partir de um determinado momento, das pesquisas nos/dos/com os cotidianos começamos a perceber que as dicotomias necessárias ao desenvolvimento das ciências, na Modernidade, estavam significando limites às idéias que formávamos nos processos destas pesquisas. Começamos, então, a escrever os pares, que aprendemos dicotomizados, desta maneira: espaçostempos, apendizagemensino, particulargeral, práticateoriaprática, dentrofora...e assim por diante.
} 
Entendemos que este caminho de ‘elucidação’ precisa ser também trabalhado em relação a nossos valores: adquiridos a 'conta gotas' em nossas vivências das redes cotidianas de conhecimentos e significações - dentro do que é entendido com “vida comum” - precisam ser aí mesmo elucidados e trabalhados. Ver-se a si mesmo trabalhando com o outro, entendendo-o como legítimo Outro (MATURANA, 1997), em torno de um projeto comum que nos ajude a tecer nossas idéias em conjunto, na criação de objetos materiais, discutindo tanto sua materialidade, como conhecendo sua espiritualidade, pode ajudar a superar as dificuldades herdadas de uma violenta convivência de séculos e de preconceitos nela adquiridos. Ou não? Sem querer determinar o que é vivido, pois isto é impossível ("Viver não é preciso”), mas apostando na esperança, sempre, lembramos algo que Bloch (2006) ensinou ao escrever:

\begin{abstract}
O tudo no sentido identificador é um em-absoluto daquilo que os homens no fundo querem. Desse modo, essa identidade mesma está depositada no fundo escuro de todos os sonhos acordados, de todas as esperanças e utopias, e é igualmente o fundo dourado sobre o qual as utopias concretas são aplicadas. Todo sonho diurno sólido refere-se a esse fundo duplo como pátria: ele é a experiência ainda não encontrada, a ainda-não-experiência experimentada em cada experiência que ocorreu até o momento (p.310).
\end{abstract}

Entendo que essa esperança é possível porque os cotidianos, com suas tantas e tão diferentes redes de conhecimentos e significações, como nos ensinou CERTEAU (1994), é uma imensa reserva constituindo os esboços ou os traços de 'desenvolvimentos diferentes' possíveis e que sempre existiriam e existem. Isto leva a que este autor afirme, ainda, que a coerência da proposta vencedora, a panótica, é

\footnotetext{
o efeito de um sucesso particular, e não a característica de todas as práticas tecnológicas. Sob o monoteísmo aparente a que se poderia comparar o privilégio que garantiriam para si mesmos os dispositivos panópticos, sobreviveria um 'politeísmo' de 'práticas disseminadas', dominadas, mas não apagadas pela carreira triunfal de uma entre elas (p.115).
}

Trabalhar com essas múltiplas 'outras’ práticas é, assim, possível porque os dispositivos e procedimentos hegemônicos passam a sê-lo na medida em que são capazes de realizar uma análise total da sociedade, de suas instituições e dos movimentos que nela se dão, a partir de sua própria lógica, ou seja, aquela que os transformou em hegemônicos e que, portanto, será também hegemônica. Isto significa que junto, no mesmo processo, perde a capacidade de analisar e até mesmo admitir todas as outras lógicas possíveis e existentes no mesmo espaçotempo, porque dele se apropriou e o entende como sendo seu. Os múltiplos 
processos cotidianos de 'lidar com a vida', em sua infinita condição de ‘criar saídas', não são sequer imaginados pelo modo hegemônico de criar, que não os consegue ver, já que não contam com um lugar próprio, como o que a maquinaria panóptica tem. Ou seja, os praticantes dos cotidianos, o tempo todo, aproveitam a ocasião, que esta cegueira nos processos hegemônicos permitem, atuando nos mesmos lugares nos quais estes se realizam. As táticas se dão onde ninguém espera, captando no vôo as possibilidades oferecidas por um instante (CERTEAU, 1994), não contando, nunca, com a segurança daquilo que o já estabelecido fornece às estratégias hegemônicas. Considerando que a tática é a arte do fraco e que as artes se colocam para além da racionalidade dominante, jogando com as emoções, CERTEAU (1994, p.101) indica que são criadas, permanentemente, combinando possibilidades, e fazendo surgir inúmeras alternativas, em trajetórias que não podem ser previamente determinadas porque serão sempre diferentes e diversificadas. Chamando Kant como apoio, em certo momento de seu texto, CERTEAU (1994) lembra que há uma arte de fazer na qual é preciso reconhecer uma arte de pensar e que, por isso mesmo, as táticas formam um campo de operações dentro do qual se desenvolve também a produção da teoria. A teoria não fica nem do lado de fora, nem pode ser vista como dicotomizada, menos ainda entendida como posterior à prática. É por isso que nas pesquisas nos/dos/com os cotidianos não se pode escapar da unidade práticateoriaprática, tanto quanto de sua crítica permanente.

É por isto que, na pesquisa desenvolvida, entendemos que a criação prática de artefatos tecnológicos permite o questionamento permanente tanto das práticas históricas de racismos, como das invenções de práticas científicas que os justificaram, com isso identificando melhor a necessidade de sua superação, no reconhecimento das tantas contribuições culturais dos afro-brasileiros, em sua materialidade e espiritualidade, em nossas vidas.

\section{A NECESSIDADE DE SE VER NA IMAGEM COM O OUTRO}

Antes de 'narrar' e analisar a experiência vivida, em palavras e em uma interpretação 'pessoal'² dos processos na pesquisa referida, convido os leitores/leitoras a

\footnotetext{
${ }^{2}$ Esse pessoal entre aspas é para fazer notar que nada é muito pessoal em pesquisa: a 'fabricação' das fotografias, a 'leitura' das imagens, sua organização e mesmo as interpretações que eu possa fazer têm, sempre, a marca de todos os membros do Grupo de pesquisa.
} 
passear dentro de uma coletânea de fotografias, em duas séries organizadas por mim e para o que conto com a imaginação de todos/todas:

\section{O MOVIMENTO ${ }^{3}$.}

\section{A CONCLUSÃO}

\section{A IMPORTÂNCIA DO TRABALHO CONJUNTO NO DESENVOLVIMENTO DE CURRÍCULOS}

Para trabalhar, de modo diferente, a questão das cotas, discutida com intensidade na UERJ, uma das primeiras instituições a admiti-las, no Brasil, organizei o projeto $^{5}$ que permitiu o desenvolvimento da pesquisa de que este artigo é um dos resultados. Nele a questão era: através o uso (CERTEAU,1994) pedagógico e curricular, em curso de formação de pedagogos, de artefatos culturais múltiplos que permitem mostrar as influências dos afrodescendentes no estado e no país, buscando entender, criticar e superar as 'marcas' diferentes deixadas pelos processos escolares discriminantes nos alunos pobres e afro-descendentes e em outros alunos, pensando em como formar os professores que têm que lidar com essas questões nas escolas, na solidariedade e em ações coletivas. Entendo que esses processos ajudam a superar, talvez, os preconceitos raciais, pois fornecem elementos aos jovens professores para “entrarem na luta”. Os processos desenvolvidos vão permitindo entender que esses artefatos, em sua materialidade, são portadores - ou podem ser - de todo um 'acervo imaterial' de memórias, crenças e valores de práticas anteriormente desenvolvidas e esperanças passadas e atuais. Além disso, esses processos permitem, também, compreender que os preconceitos não desaparecem com discursos - orais ou escritos - mas sim que desaparecem com ações compartilhadas, com memórias lembradas e superadas juntos, já que têm sempre que ver com todos os praticantes das redes cotidianas, tanto os que são discriminados como os que discrimimam. Suas marcas estão em todos, embora de modo agudamente diferente, e só os podemos mudar se agirmos e discutirmos em conjunto, sobre eles, criando juntos outras possibilidades de vivermos juntos.

\footnotetext{
${ }^{3}$ Power Point 1: http://www.fe.unicamp.br/acamorim/O-Movimento-NildaAlves.ppt

${ }^{4}$ Power Point 2: http://www.fe.unicamp.br/acamorim/As-conclusoes-NildaAlves.ppt

${ }^{5} \mathrm{O}$ projeto tem o título seguinte: "Artefatos tecnológicos relacionados à imagem e ao som na expressão da cultura de afro-brasileiros e seu 'uso' em processos curriculares de formação de professoras na Educação Superior - o caso do curso de Pedagogia da Uerj/campus Maracanã.” Foi desenvolvido de agosto/2005 a julho/2008.
} 
Assim, a produção de artefatos culturais diversos - livros infantis, almanaque, estandartes e livros de cordel - criados em sucessivos semestres ${ }^{6}$ e para o que concorriam múltiplas práticas (apresentação didática de textos teóricos; utilização de inúmeros artefatos curriculares/pedagógicos/didáticos - livros infantis sobre afro-descendentes; almanaques; power points; discos; livros teóricos etc; discussões sobre narrativas de experiências múltiplas nas redes de conhecimentos e significações em que vivemos; reprodução de obras de diversos artistas: nas artes plásticas; na música; na literatura etc) foram permitindo que se discutisse a questão central do projeto. Todas estas atividades se deram sempre em grupo, inserida em uma discussão da responsabilidade individual nos processos desenvolvidos. Esses sucessivos encontros e as "conversas" ${ }^{, 7}$ neles desenvolvidas foram sendo fotografados e registrados em vídeo, formando o ‘corpus’ desejado para a pesquisa.

\title{
SOBRE CULTURAS E COTIDIANOS $^{8}$ - OS 'ESPAÇOSTEMPOS' DOS ARTEFATOS CULTURAIS NAS REDES COTIDIANAS
}

Williams (1992) em seus estudos sobre os espaçostempos das tecnologias comunicacionais na história humana, caracterizou o que entende ser técnica, invento técnico, tecnologia e engenho técnico, a que venho preferindo chamar de artefatos culturais (ALVES, 2003). Diz esse autor

\begin{abstract}
uma técnica é uma habilidade particular ou a aplicação de uma habilidade. Um invento técnico é, por conseguinte, o desenvolvimento desta habilidade, ou o desenvolvimento ou invenção de um de seus engenhos. Em contraste, uma tecnologia é, em primeiro lugar, o marco de conhecimentos necessários para o desenvolvimento desta habilidade e suas aplicações e, em segundo lugar, o marco de conhecimentos e condições para a utilização e aplicação de práticas de uma série de engenhos (p.184).
\end{abstract}

Seguindo esta idéia, venho entendendo que os seres humanos, em suas ações e para se comunicarem, estão carregados de valores que reproduzem, transmitem, mas também criam, nos contatos que têm entre si e com toda a produção técnica e artística. Assim, em um

\footnotetext{
${ }^{6}$ A pesquisa empírica foi desenvolvida em seis semestres sucessivos (do $1^{\circ} / 2005$ a $2^{\circ} / 2007$ ) no componente curricular Pesquisa e Prática Pedagógica (PPP) do Curso de Pedagogia da UERJ, no campus do Maracanã.

${ }^{7}$ No Grupo de pesquisa temos preferido usar, sempre, este termo a qualquer outro por julgarmos que é isto que acontece, nessas situações, nas quais os seus integrantes trocam idéias. Usamos a idéia de Coutinho (1997) sobre isto.

${ }^{8} \mathrm{O}$ uso do plural nesses termos tem a ver com a posição teórico-epistemológica que incorpora a idéia de que vivemos em múltiplos contextos cotidianos que formam redes complexas de toda ordem, incluindo as culturais.
} 
mesmo processo, vão aplicando tanto o que lhes é imposto pela cultura dominante (produtos técnicos colocados à disposição para consumo) como vão criando modos de usar e conhecer o invento técnico, fazendo surgir tecnologias diferentes nesses usos e possibilidades de mudanças tanto dos artefatos técnicos, como das técnicas de uso, fazendo-os artefatos culturais. A compreensão desses processos só se torna possível articulada com a idéia de tessitura de conhecimentos e significações em redes, entendendo que essas são espaçostempos de trocas significativas para os praticantes dos/nos/com os cotidianos, nas quais tecem conhecimentos de todo tipo, em especial aqueles dos quais não sabemos, de modo espantâneo, a origem, do uso de uma colher, ao uso da língua materna, aos preconceitos de todo tipo.

Nos processos de pesquisa, foi indispensável compreender que no caso dos cotidianos escolares - todos eles, inclusive os dos cursos de formação de professoras - e ao contrário do que foi dito em outras pesquisas e em certos modos de pensar a escola, é impossível a existência de 'muros' entre as escolas e os “contextos externos” ou a "vida”. Isso porque, como é dito por Santos (1995) somos, cada um de nós, uma rede de subjetividades formada nos tantos contextos cotidianos de que participamos. Ou seja, cada conhecimento (valor, arte ou tecnologia) aprendido ou criado, entra nas redes educativas todas, sempre, porque encarnado em cada um de seus praticantes.

Tudo o que se fabrica - se cria/transmite/reproduz - no uso de tantos artefatos culturais postos à disposição para o consumo poderá ser compreendido se incorporamos a idéia de redes de relações entre os vários contextos cotidianos nos quais vivemos, explicada tanto pela indisciplina do uso (CERTEAU, 1994), como pelos processos de hibridização desses/nesses produtos (CANCLINI, 1995). Compreender as táticas dos praticantes (CERTEAU, 1994) e as relações de comunicação entre os mesmos (MARTIN-BARBERO, 2000;1997) é como se torna possível indagar como se dão tanto as manutenções como as mudanças, as repetições e as novidades, em processos curriculares nas redes educativas. É como trabalham esses autores tão diferentes: assumindo os praticantes dos cotidianos em seus contatos com os artefatos técnicos como criadores de sua história, e não 'passivos' ou 'alienados' - como pensam alguns - pois, permanentemente, criam valores e articulam práticas éticas e estéticas, ao mesmo tempo, em que usam técnicas e criam tecnologias.

Sendo assim, seguir a memória de praticantes dos currículos através de histórias que são lembradas em momentos de ‘produção' de artefatos culturais ligados a culturas que contribuíram em sua formação em múltiplas redes cotidianas, permite o surgimento dos 
conflitos do passado e do presente, ao mesmo tempo em que cria possibilidades de superação dos mesmos. Permite fazer surgir, talvez, diálogos que passam a indicar outras possibilidades de vivência e convivência a partir do auxílio mútuo, do aprender a contar história e de ouvilas em comunidade, em conjunto, de criar novas possibilidades de trabalho, no que se refere às práticas docentes.

Tudo isso, porque se faz um deslocamento do problema a estudar, da questão a responder. Luce Giard, ao introduzir os trabalhos de Certeau (1994) sobre cotidianos, vai indicar que a grande "empreitada teórica” deste autor se refere à busca de compreender não os produtos culturais oferecidos no mercado de bens, mas sim as operações dos seus usuários (p.13), indicando as maneiras diferentes de 'marcar' socialmente o desvio operado num dado por uma prática ${ }^{9}$, na tentativa de responder “a questão indiscreta”: como se cria? (p.12).

Nos processos, portanto, de 'conversar' sobre idéias e de produzir artefatos, as práticas desenvolvidas permitiram indicar que há uma maneira de pensar investida em uma maneira de agir, uma arte de combinar indissociável de uma arte de utilizar (CERTEAU, 1994, p.42). É por isso que se torna imprescindível compreender que os praticantes nas redes cotidianas fazem sua síntese intelectual não pela forma de um discurso, mas pela própria decisão, ato e maneira de aproveitar a 'ocasião' (p. 47). Dessa maneira, o surgimento nas conversas estabelecidas entre os praticantes, durante a criação de artefatos, de narrativas sobre outras práticas permitiu tanto a compreensão do sentido cultural daquele artefato, como das significações teóricas ou ideológicas que o cercam, na história da humanidade e no passado/presente brasileiro.

\section{CULTURAS $^{10}$ DE AFRO-BRASILEIROS E CURRÍCULOS PRATICADOS}

Compreender as possibilidades de considerar como as heranças culturais dos afrobrasileiros estão presentes nos currículos praticados das escolas, em especial no caso da formação de professoras na Educação Superior, significa concordar com a idéia que elas estão encarnadas nos praticantes dos currículos a partir de múltiplas vivências nas tantas redes de conhecimentos e significações nas quais todos vivem: seja pela sua negação ou pela sua

\footnotetext{
${ }^{9}$ A autora cita, aqui, um trecho do livro Cultura no Plural, de CERTEAU (1992).

${ }^{10} \mathrm{O}$ plural nesse termo tem em vista marcar as múltiplas origens africanas e, portanto, as diferenças culturais dos afro-descendentes no Brasil.
} 
posse; seja por qualquer dos lados que ocupemos em processos de exclusão ou de articulação; seja porque conseguimos ver e compreender o preconceito, seja por que sequer o vemos, negando sua existência. .

Dessa maneira, buscar entender como essa questão está presente na realização de um curso concreto, exige que se tenha por dado, no ponto de partida, que essas heranças, mantidas por determinados grupos e contra a vontade de outros, em uma determinada sociedade, no caso a brasileira, tem a ver com redes que envolvem tanto uns, como os outros (ALMEIDA, 2004). Não se trata, então, de se viver uma experiência que vai interessar aos afro-brasileiros, alunos/alunas do referido curso, mas que tem a ver com marcas incorporadas à vida de todos/todas que vivem essa história, nas redes múltiplas pelas quais se relacionam uns/umas com os outros/outras, que têm o que contar sobre isto, que acumulam memórias sobre essas situações. Por outro lado, significa admitir, ainda, que a formação de todos/todas os/as estudantes que esse curso incorpora, mesmo que não esteja no que poderíamos chamar de 'currículo declarado,"11, tem a ver com essas questões - elas estão presentes o tempo todo, em todos os espaçostempos dos currículos praticados ${ }^{12}$, quer queiramos ou não, quer possamos ver ou não sua presença, nas relações entre os diversos praticantes dos currículos.

\footnotetext{
${ }^{11}$ Aqueles processos que articulam tanto o que foi assumido institucionalmente, pelos organismos decisórios, como o que vai sendo declarado, politicamente, pelos inúmeros praticantes do mesmo, como aquilo que é, o que deveria ser etc.

${ }^{12}$ Entendemos que são aqueles processos que são praticados nos diversos contextos de formação existentes.
} 


\title{
CLEMENTINA CADÊ VOCÊ? ${ }^{13}$
}

\begin{abstract}
Não havia parâmetros nem similaridades para avaliar aquela voz singular, rascante e musguenta, soando que nem tambores africanos, rompendo com todos os manuais então vigentes - e um deles, em especial, codificando uma forma mais introspectiva de cantar.

Estávamos em dezembro de 1964, ano violentado pelo golpe militar que instituiu um novo estado de direito. Se a mordaça da censura ainda não baixara com a truculência que exibiria quatro anos depois com o Ato Institucional n. 5, eu temia um outro tipo de censura, a estética, porque as comparações seriam inevitáveis. Como bem explicitou o pesquisador Ary Vasconcelos: 'em nossos ouvidos mal acostumados pela seda e pelo veludo produzidos pelos cantores da época, a voz de Clementina penetrou como uma navalha. A ferida ainda está aberta e sangra, mas isso é saudável: serve para nos lembrar que a África permanece viva em nós'.

Aquela humilde doméstica, negra e com 63 anos, não se enquadrava em nenhum dos protótipos da época: era o oposto da instrospecção de João Gilberto e Nara Leão, modelos da bossa nova surgida seis anos antes. E, também, qualquer conceito convencional de beleza vocal não poderia equivalê-la à imponência clássica da Divina Elizeth, então o paradigma de intérprete mais reverenciado pela crítica. Ainda se rascunhava o aparecimento de três vulcões de extroversão, que iriam aparelhar a música popular com vozes amplas, temperadas com açafrão e curau: Elis Regina, Maria Bethânia e Gal Costa. (CARVALHO, 2001, p.40)
\end{abstract}

Ao tomarmos ${ }^{14}$ a decisão de trabalhar, no $2^{\circ}$ semestre de 2006, o estandarte como artefato cultural, para mostrar sua presença em todas as culturas, desde há muito, entendemos que isto deveria ser feito com a história de alguém que, muito provavelmente, seria desconhecido pelos estudantes/companheiros de caminho que nos acompanhavam na trajetória dessa pesquisa: a cantora Clementina de Jesus, descoberta por Hermínio Bello de Carvalho, em 1964.

Para tanto, além de trazermos para a sala livros com imagens de estandartes usados em diversas culturas e diversos espaçostempos para leitura e discussões, trouxemos o livro Rainha Quelé - Clementina de Jesus (CARVALHO et. al, 2001) com textos sobre Clementina de Jesus e sua importância para a música do Rio de Janeiro e do Brasil e um disco gravado por ela para que, os que a desconheciam, pudessem perceber o que era e significava aquela voz singular, rascante e musguenta e como e porquê penetrava como uma navalha, deixando uma ferida que ainda está aberta e sangra. A beleza nada convencional daquela figura negra e daquela voz 'estranha' causou um grande impacto e nos movimentou para o

\footnotetext{
13 "Clementina cadê você” é um refrão de música cantada por Clementina de Jesus e que foi feita em sua homenagem por Hermínio Bello de Carvalho

${ }^{14}$ Este nós refere-se a mim e a Mailsa Passos, professora adjunta da UERJ, com quem partilhei esta experiência curricular e de pesquisa. Dedico este artigo a ela.
} 
trabalho. Fomos à internet buscar outras imagens e outras 'informações' sobre ela, para transformá-la no 'motivo' dos estandartes que faríamos. Acompanhando esse trabalho, fizemos a leitura de textos diversos que eram apresentados por duplas de estudantes a todos nós sobre as culturas negras no Brasil e no mundo, em especial, naquele semestre, sobre os movimentos da música negra no Brasil e no mundo. Nesses processos, surgiam as vozes dos estudantes, em sua diversidade, que a partir de sua memória de desconhecimento de Clementina, lembravam outros artistas e narravam algumas histórias de suas experiências com músicas e músicos afro-brasileiros e de origem africana em outro país e na África de hoje.

Assim, conhecendo essa artista potente e a história em que estava inserida pessoal, social e cultural - pudemos decidir sobre como representar sua vida em estandartes, discutindo quanto o 'uso' a ser feito dos inúmeros artefatos que tínhamos à mão, tanto como 'conversamos' sobre racismo, em histórias pessoais e coletivas, estabelecendo diálogos no grupo menor de criação do estandarte, generalizados para a turma, muitas vezes.

Ao final, quando se mostraram os artefatos tão diferenciados que tinham sido criados e produzidos, pudemos perceber: o amor que Clementina tinha despertado em todos e todas e o orgulho que tinha despertado em nós (pertencíamos à mesma terra em que ela vivera e à multiplicidade cultural de que participara, produzindo com sua voz um mundo melhor); as condições de trabalharmos juntos usando o que cada um tinha de melhor ou o que desejava fazer (Será que sei bordar? Como se coloca linha em agulha? Para que servem estas fitas e estas tintas? - as respostas a essas questões foram encontradas entre risos e ajudas mútuas e até manchando a calça da professora com uma tinta que não foi possível lavar, aprendendo que isto existe!); as diferenças e a complementariedade de trabalhos de homens e mulheres, em suas delicadezas, gentilezas e interesses (afinal, existe trabalho de homem diferente de trabalho de mulher? - foi uma questão bastante discutida); a variedade de técnicas usadas que mostravam as formas diferentes de produzir uma mesma história (com suas possibilidades múltiplas!); a escolha de diferentes de 'momentos' ou de 'acontecimentos' da vida de Clementina de Jesus que ao final nos permitiu - ao verificar o conjunto formado por cada estandarte produzido - organizar idéias de modo a entender que formavam uma história maior do que aquela que cada parte nos permitia compreender, sabendo que ainda faltavam coisas, já que mais se poderia contar - e concluir que é assim na vida: partestodo; práticateoriaprática; individualcoletivo; concretoabstrato; dentrofora da escola! 


\section{REFERÊNCIAS}

ALMEIDA, M. J. Investigação visual a respeito do outro. In: GALLO, S.; SOUZA, R. M. Educação do preconceito: ensaios sobre poder e resistência. Campinas: Alínea, 2004. p. 29 68.

ALVES, N. Cultura e cotidiano escolar. Revista Brasileira de Educação, Rio de Janeiro: ANPEd, maio/ago 2003 b, n.23, p. 62 - 74.

BLOCH, E. O princípio da esperança. Rio de Janeiro: Contraponto/EdUerj, 2006, vol. 1.

BOULIER, D. Modes d'emploi: réinvention et traduction des techniques par l'usager. In: GRAS, A. et. al (Org.). Sociologie des techniques de la vie quotidienne. Paris: L'Harmattan, 1992.

CANCLINI, N. G. Culturas híbridas: estrategias para entrar y salir de la modernidad. $2^{\mathrm{a}}$ ed. Buenos Aires: Editorial Sudamericana, 1995.

CARVALHO, H. B. Clementina: uma nova estética. In:

Clementina de Jesus. Rio de Janeiro: Finep/CTBrasil, 2001. p. 40 - 47.

CERTEAU, M. A invenção do cotidiano: as artes de fazer. Petrópolis: Vozes, 1994.

Cultura no plural. Rio de Janeiro: Ed 37, 1992.

COUTINHO, E. O cinema documentário e a escuta sensível da auteridade. In: ANTONACCI, M. A.; PERELMUTTER, D. (Orgs). Projeto história: ética e história oral. São Paulo: PUC/SP, abr./97, n.15. p. 165 - 191.

MACHADO, A. O quarto iconoclasmo e outros ensaios herejes. Rio de Janeiro: Rios Ambiciosos, 2001.

MATURANA, H. A ontologia da realidade. Belo Horizonte: Ed. UFMG, 1997.

MARTIN-BARBERO, J. Novos regimes de visualidade e descentramentos culturais. In: FILÉ, V. (Org). Batuques, fragmentações e fluxos: zapeando pela linguagem audiovisual no cotidiano escolar. Rio de Janeiro: DP \& A , 2000. p.83 - 112.

Janeiro: Ed.UFRJ, 1997.

Dos meios às mediações: comunicação, cultura e hegemonia. Rio de

SANTOS, B. S. Pela mão de Alice: o social e o político na pós-modernidade. São Paulo: Cortez, 1995.

WILLIAMS, R. História de la comunicación: de la imprenta a nuestros dias. Barcelona: Bosch, 1992. 


\section{Agradecimentos:}

Pesquisa com apoio do CNPq e da FAPERJ/UERJ

(O direito ao uso das fotografias existe firmado por todos

e todas que nelas aparecem; essas imagens pertencem ao

Banco de Imagens/Laboratório Educação e

Imagem/UERJ)

\section{NILDA ALVES}

Professora titular da Universidade do Estado do Rio de Janeiro (UERJ).

Coordenadora do

Laboratório Educação e Imagem (www.lab-eduimagem.pro.br).

Pesquisadora do CNPq.

UERJ/PROPEd

E-mail: nildalves@uol.com.br

Recebido em: 10/03/2008

Publicado em: 20/10/2008 